\title{
Role of reef fauna in sediment transport and distribution
}

\author{
Studies from Tektite I and II
}

\author{
H. E. Clifton \\ U.S. Geological Survey; Menlo Park, California, USA
}

KURZFASSUNG: Die Rolle dex Riffauna beim Transport und der Verteilung des Sediments. Untersuchungen von Tektite I und II. Die Tierwelt scheint einen größeren Einfluß auf die Verfrachtung und Verteilung von Sedimenten in der Umgebung von Korallenriffen auszuüben als physikalische Vorgänge. Versuche, die während der "Man-in-the-sea" Projekte Tektite I und II bei St. John, U.S. Virgin Islands (Karibische See), durchgeführt wurden, galten unter anderem Studien ibber das Ausmaß des Transportes von Sedimentbestandteilen durch Fische. Ferner wurde die Geschwindigkeit, mit der Rippeln und Schichtungen durch tierische Wühlvorgänge zerstört und mit der Steine und andere Substratteile durch das Unterwühlen von Tieren umgelagert werden, untersucht. Ergänzende Beobachtungen wurden über die Orientierung leerer Muschelschalen angestellt, die je nachdem, ob sie von Bodentieren oder durch Wellen und Strömungen bewegt werden, entweder mit der konkaven Seite bevorzugt nach oben oder nach unten gelagert werden. Verschiedene Probleme der Beziehungen zwischen Riffauna und Sediment werden diskutiert.

\section{INTRODUCTION}

A number of geologic processes are involved in the production of a sediment and determine its ultimate character. The major processes include those that are responsible for producing the source material, those that result in its fragmentation and the distributive processes involved in sediment dispersal and accumulation.

For most sediments these processes are largely inorganic. Physical and chemical reactions control the composition and texture of most source material. In most environments, the combined processes of chemical weathering and physical erosion mechanically reduce this material. Waves and currents govern the distribution of most of this sediment over the sea floor.

In the tropical reef environment, however, biological activity is involved in nearly all aspects of sedimentation. The skeletal frameworks of a variety of organisms form the predominant source of sediment. The fragmentation of this material results largely from faunal activity, which also can strongly influence the distribution of this sediment.

Participation in the man-in-the-sea projects Tektite $I$ and II provided an excellent opportunity to observe the impact of reef faunas on geologic processes. In both experiments the habitat was located at a water depth of about $15 \mathrm{~m}$ adjacent 
to a thriving coral reef (Fig. 1) on the east side of Lameshur Bay on the south side of St. John, U.S. Virgin Islands. Tektite I, in 1969, and Tektite II, in 1970, afforded 60 and 20 days of continuous underwater research, respectively. In addition, diving research was conducted from the surface before and after each experiment. During Tektite I a variety of geological problems were investigated (CLIFTon et al. 1970), but during Tektite II research centered specifically on the interaction of fauna and sediment.

The importance of organisms in the production and fragmentation of carbonate sediment has already been documented by a number of studies, whereas far less is known about the influence of organisms on sediment distrubution. Therefore most of my research during the Tektite experiments concerned the distributive influence of reef fauna. This paper describes this research, documenting the extent to which faunas transport and modify sediment near a coral reef.

\section{DESCRIPTION OF RESEARCH}

Reef faunas become distributive agents by two different processes. Some organisms selectively remove sediment from one location and redeposit it elsewhere. Others indiscriminately mix previously deposited material, thereby altering its original horizontal and vertical distribution. Aspects of both effects were studied during the Tektite program.

Fish are perhaps the most effective agents in the selective lateral transport of sediment. The Scaridae (parrot fishes) in particular actively break down and ingest coral fragments (Cloud 1959, pp. 398-399). By ingesting this material at one place and excreting it at another, these fish may effectively transport a significant amount of sand-size coralline detritus. They may thereby play a major role in the removal of sand-size debris from the reef.

Other fish, such as Malacanthus plumieri (BLOCH) (sand tilefish), incorporate coarse coral fragments and shells into the roofs of their burrows. These fish, which live on the sand flats adjacent to the reefs, may transport large quantities of such material to their burrow sites. One was observed to return 464 fragments to a partly destroyed burrow within a period of eight days (Clifton \& HunTER in press, a). The same fish picked up a few fragments 9-12 meters away from its burrow and returned them to the roof. Construction and maintenance of burrows by $M$. plumieri thus localizes and concentrates much of the coarser debris around the reef margins.

Certain invertebrates also selectively transport coarse sediment. Empty pelecypod shells are known to collect around octopus lairs (Hoskin 1963, pp. 90-91). Empty gastropod shells also accumulate around these lairs in Lameshur Bay. During Tektite II, an octopus removed a discoidal coral pebble approximately $75 \mathrm{~mm}$ in diameter and $30 \mathrm{~mm}$ thick from an experiment on pebble burial and carried it several meters to block the opening to its lair.

A great amount of sediment is scattered laterally by the random movement of crawling and burrowing fauna. The relative effectiveness of this phenomenon compared to physical processes is indicated by an experiment, begun during Tektite I 


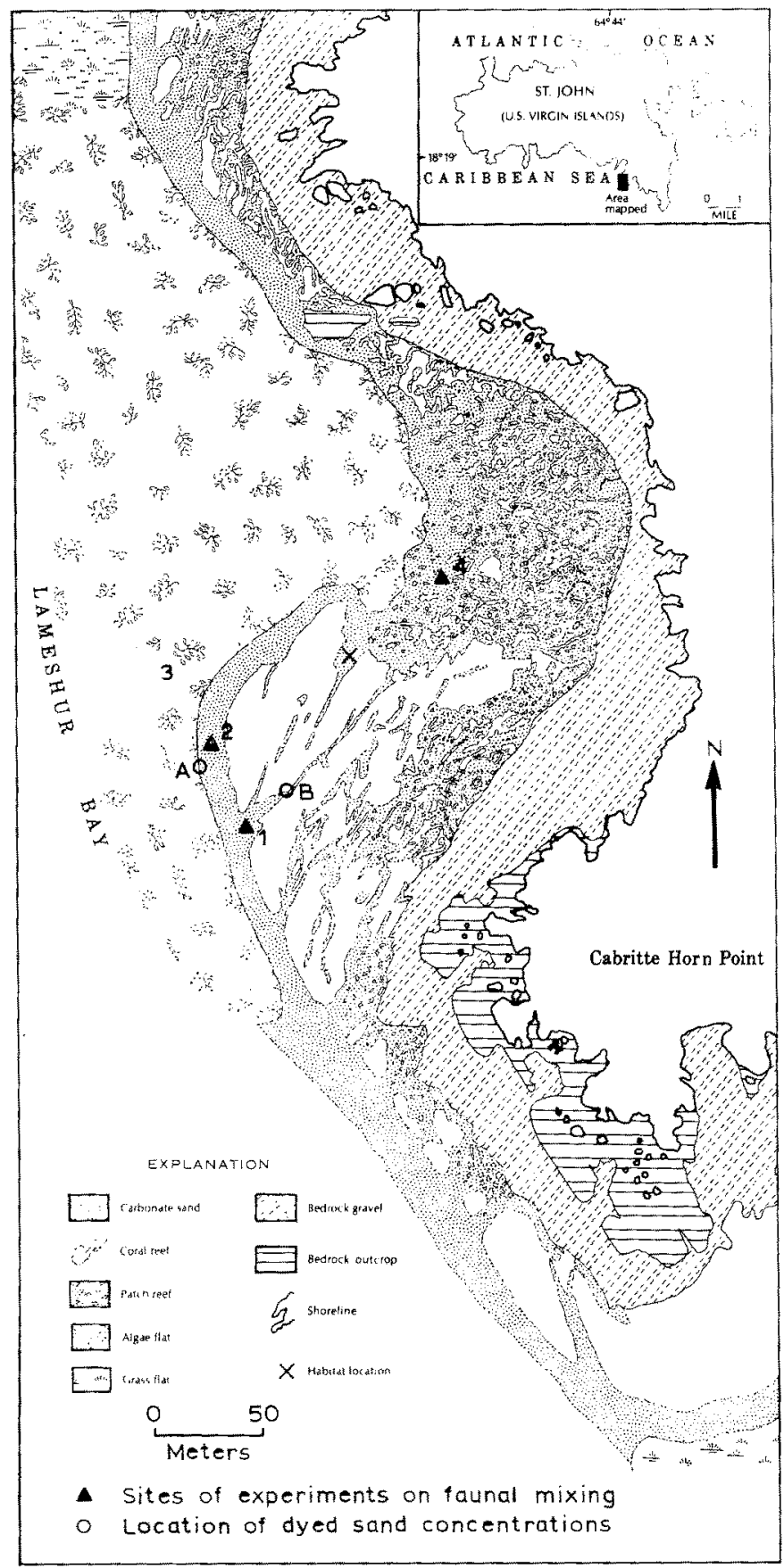

Fig. 1: Map of substrate types in vicinity of habitat, experiments Tektite I and II 
and concluded during Tektite II, that was designed to determine the rate and direction of sand transport. Approximately 500 grams of carbonate sand, dyed fluorescent red, were placed in a conical pile on the sand flat several meters from the reef margin (A, Fig. 1). A metal spike marked the center of the pile. The concentration showed no

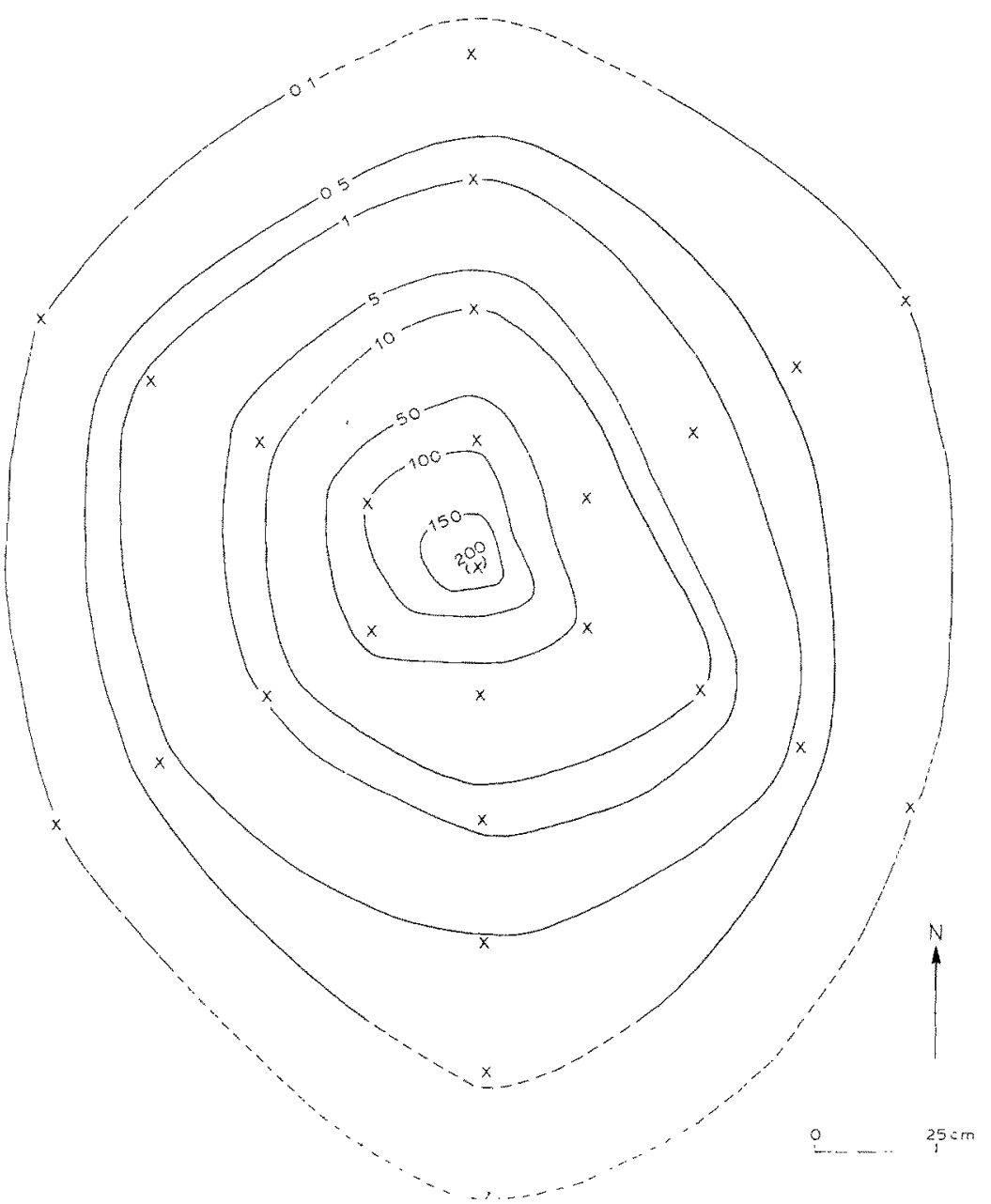

Fig. 2: Distribution of dyed sand (in grains per gram of indigenous sediment) at concentration A (Fig. 1) one year after it was placed in a conical pile at the center of the hexagonal grid. Small $x$ 's show locations of sampling. Contour lines dashed where extrapolated beyond sampling grid

obvious change by the end of Tektite $I$ and the experiment was considered inconclusive. During Tektite II, however, the sand was found to be widely scattered from the central spike, which remained in place. The surface sediment around the spike was sampled to a depth of $2 \mathrm{~cm}$ using a small $(4.6 \mathrm{~cm}$ internal diameter) coring device at $25 \mathrm{~cm}$ intervals on a hexagonal grid that extended $100 \mathrm{~cm}$ from the spike. 
The distribution of dyed grains in the sediment around the spike (Fig. 2) is nearly isotropic, implying that the dyed sand was scattered uniformly in all directions. No suggestion of significant transport by unidirectional currents is suggested by the distribution. The slight north-south elongation of the outermost contours may result from scattering caused by waves traveling in this direction. The average orientation

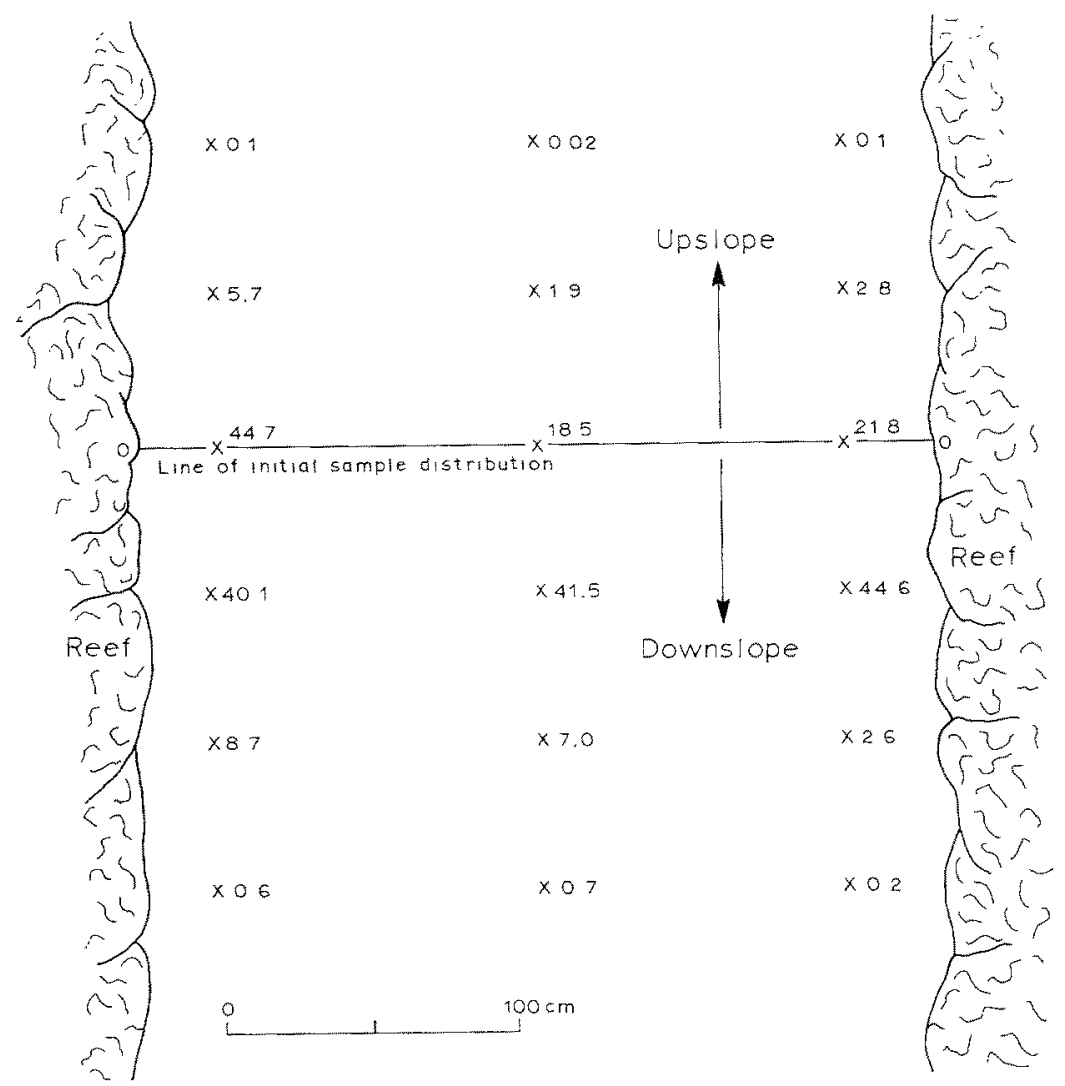

Fig. 3: Distribution of dyed sand (in grains per gram of indigenous sediment) at concentration $B$ (Fig. 1) one year after it was placed in a line across a channel trough the reef. Note displacement of maximum concentration in down slope direction

of gorgonians (sea fans) on the margin of the adjacent reef is nearly east-west, suggesting that water oscillation due to passing waves is predominantly north-south. Such waves evidently have had little effect on sediment transport, however. The scattering of the dyed sand seems to be primarily the result of randomly crawling or burrowing organisms. The experiment documents the degree to which such organisms can disperse and mix the surface sediments.

If random mixing occurs on a sloping surface, the component of gravitational force can cause a net downslope movement of material. A probable example of this is furnished by another experiment set up during Tektite I and monitored during 
Tektite II. About $1000 \mathrm{~g}$ of carbonate sand, dyed fluorescent red, were placed in a line across a narrow channel through the reef $(B$, Fig. 1 and 3$)$. The channel was partly filled with carbonate sand and sloped seaward with an inclination of about 1:9. As with the other experiment, no obvious change occurred during Tektite $I$.

A year later, however, the dyed sand was scattered and showed a distinct net displacement down the channel. Samples taken by the same means as in the other experiment at $50-\mathrm{cm}$ intervals along three lines parallel to the axis of the channel show a displacement of the maximum concentration of dyed grains downslope from the original line (Fig. 3). The spacing of the sample grid makes it difficult to ascertain exactly how far downslope the maximum concentration is displaced - certainly the displacement is no greater than $50 \mathrm{~cm}$ and it probably lies between 25 and $50 \mathrm{~cm}$. If it is assumed that only the sand in the uppermost $2 \mathrm{~cm}$ of sediment (the depth of sampling) is moving, an estimate of the volume of sand displaced downslope per year can be made. In a channel $2 \mathrm{~m}$ wide, between 10000 and $20000 \mathrm{~cm}^{3}$ of carbonate sand move in a net downslope direction in a year.

Currents flowing to the south within the channel may be responsible for some of this downslope transport. Southward net transport, however, was not observed in the other experiment, conducted along the reef front about $50 \mathrm{~m}$ away and in only slightly (less than $2 \mathrm{~m}$ ) deeper water (Fig. 1). Therefore, it seems reasonable that the transport of sand in the channel results from random biogenic mixing on a pronounced slope. The volume of material transported per year is relatively small, but with time a substantial amount of sediment may be moved down the channel in this manner.

The combination of random faunal displacement of sediment and gravitational force may also be responsible for shedding of carbonate sand from the living coral reef into the sand-floored channels or other inter-reef areas. Individual coral polyps can reject sediment which falls on them (HuBbard 1971). On a sufficient slope along the reef margin, for example, the force of gravity would likely produce a net downslope transport of sand-size sediment as it was being rejected at random direction by the living coral polyps.

Faunal mixing may substantially alter both the surface configuration and the internal character of the sediment. In many environments, physical processes alone govern the nature of these features. For example, the sediment surface, whether in the deep ocean or on shallow shelves, commonly is shaped into ripple-forms by the activity of waves or currents. The internal structure of such sediment consists primarily of lamination or cross-lamination produced by the same processes. In the quiet water of Lameshur Bay, in contrast, biogenic activity is the main process controlling the surface and internal structure.

Several experiments conducted during Tektite II demonstrated the rate and mechanisms whereby organisms modify the surface and internal structure of carbonate sand near a coral reef (Clifton \& HunTER in press, b). Each experiment was duplicated in four different settings to determine the effect of substrate type, degree of algal cover, proximity to the reef and, within limits, water depth. The experiment sites are shown in Figure 1 and described in Table 1.

To determine the rate whereby wave- or current-generated structures are modified by organisms in this environment, a set of eight simulated ripples were shaped by 
Role of reef fauna

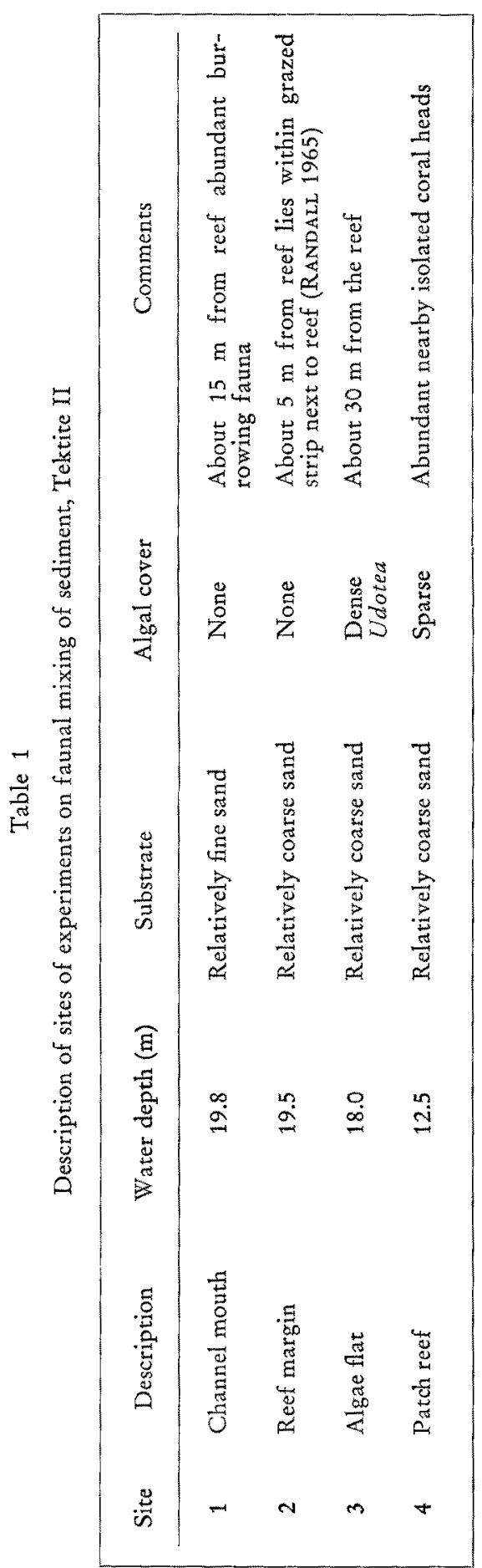


hand and left to the activity of the organisms. The ripples, $5 \mathrm{~cm}$ high, $100 \mathrm{~cm}$ long and $20 \mathrm{~cm}$ apart, resembled those formed by waves in water about $10 \mathrm{~m}$ deep off parts of the southern coast of St. John exposed to incoming swell. These structures were not influenced by waves or currents during the experiment. They did, however, become progressively modified and finally completely obliterated. The rate of modification differed among the plots: in the channel-mouth site the ripples disappeared within 15 days; in the other sites they persisted from 24 to 35 days. The rapid rate of ripple destruction in the channel mouth seemed to result primarily from the intensity of burrowing at that site. Organisms within the sediment eject sediment from their burrows and thereby produce mounds of sand upon the surface that quickly change the microtopography. In the other sites, ripples were destroyed by organisms crawling over or through the upper layer of the sediment.

The rate of disruption of internal structure was monitored in another experiment. Artificial bedding, consisting of two layers of dyed carbonate sand, each $2 \mathrm{~mm}$ thick, separated and covered by layers of indigenous sand, 3 to $5 \mathrm{~mm}$ thick, was prepared at each site in a small plot $25 \mathrm{~cm}$ wide by $100 \mathrm{~cm}$ long. Cores were taken at 4-day intervals with small Senckenberg boxes, which provide undisturbed sections about $15 \mathrm{~cm}$ wide by $5 \mathrm{~cm}$ deep.

As with the ripple experiment, the rate of destruction differed from one plot to the next. However, the laminations lasted longer at the channel-mouth site than at the other sites (Fig. 4). Apparently, isolated burrowing (predominantly in the vertical direction) disrupts lamination near the surface less than does the crawling or horizontal burrowing near the surface that predominates at the other sites. Also sand cast upon the surface by burrowing organisms covers and may protect internal structure near the surface. In every experiment the upper lamination was consistently more disrupted than the lower (Fig. 4).

Another experiment demonstrated the ability of organisms to bury solid objects such as pebbles, cobbles, and empty shells. This is a potentially important geologic process for it incorporates material into the sediment column. Moreover, once below the sediment-water interface, the pebbles or shells are no longer susceptible to biological or physical erosion.

To determine the rate at which clasts of different size, shape, and composition are buried by the activity of organisms, a set of 22 pebbles was placed on the bottom at each of the experiment sites. Each set consisted of two each of the following: small spherical (about $4 \mathrm{~cm}$ in diameter) pebbles of bedrock and coral, small flat (about 2 by $5 \mathrm{~cm}$ ) pebbles of bedrock and coral, medium round (about $6 \mathrm{~cm}$ in diameter) pebbles of bedrock and coral, medium flat (about 3 by $8 \mathrm{~cm}$ ) pebbles of bedrock and coral, round (about $10 \mathrm{~cm}$ in diameter) cobbles of bedrock and coral, and flat (about 5 by $10 \mathrm{~cm}$ ) cobbles of bedrock. The pebble plots were monitored periodically, and all pebbles were excavated after 32 days to determine how deeply each was buried.

Several different effects were observed during the course of the experiment. Very commonly, the pebbles would be lightly to heavily covered with a dusting of sand thrown into the water by organisms digging nearby. In all plots the pebbles, particularly the flatter ones, tended to sink a centimeter or two into the sand. In the channel-mouth plot, many of the pebbles covered small burrows, most of which seemed 
to have been dug by small fish, mainly gobies. Such pebbles sank rather rapidly into depressions in the sand. In every plot pebbles were displaced by organisms moving across the sand: one of the largest bedrock cobbles was moved several centimeters and some of the smaller pebbles were displaced even farther.

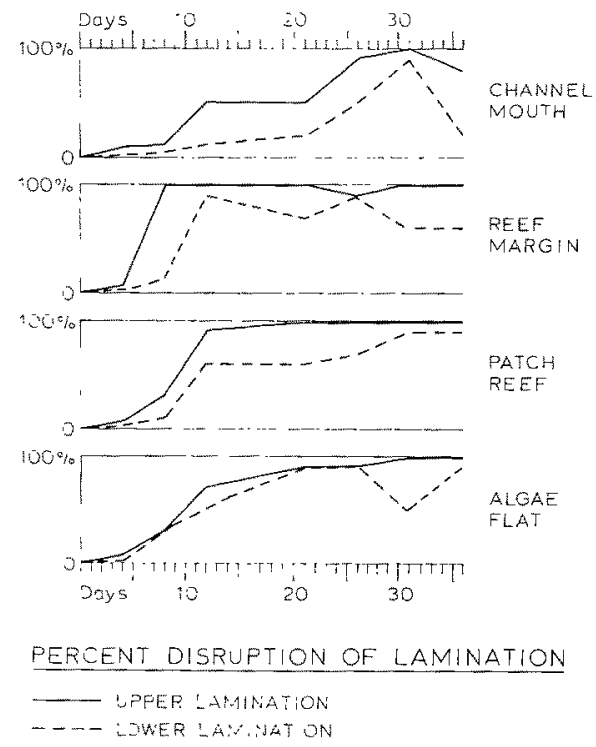

Fig. 4: Estimated degree of disruption of artificial laminations through time at each experiment site

After 32 days, two parameters were measured for each pebble remaining in the plots: (1) the distance from the top of the pebble to the surface of the sand above or below, which indicates the degree of burial of the pebble, and (2) the distance from the base of the pebble to the sand surface above, which indicates the depth to which the pebble sank and, unlike the first parameter, is independent of pebble size (thickness).

By averaging the data for each type of clast from all four plots, the depth of burial and depth of sinking can be related to clast size, shape, and composition. The averages indicate that depth of sinking, approximately $2 \mathrm{~cm}$ for all types, is not related to the dimension or the density of the clast. The depth of burial is related to size and shape but not to composition of the clast. The relation to size and shape is predictable; for pebbles and cobbles which sink more or less the same distance into the sand, the smaller and flatter are likelier to become buried.

The experiment demonstrated that the depth of sinking and burial is related to the grain size of the substrate. In the channel-mouth plot, undermining was active, and the top of the pebbles lay on the average nearly even with the sand surface; in the other three plots, where grain size is coarser (Table 1), the tops of the pebbles were an average of 2.5 to $3.5 \mathrm{~cm}$ above the sand surface. The average depth of sinking of the pebbles in the channel-mouth plot was nearly $4 \mathrm{~cm}$, whereas that in the other plots was only about 1-2 cm. Of the clasts in the channel-mouth plot, the most deeply 
buried were a large flat bedrock cobble that sank to a depth of $8 \mathrm{~cm}$ and lay (from its top) $3.5 \mathrm{~cm}$ beneath the surface and a small flat coral pebble that sank to a depth of $5 \mathrm{~cm}$ and lay (from its top) $4 \mathrm{~cm}$ beneath the surface. The plots in the reef margin and the patch reef sites contained 2 or 3 pebbles that were completely buried. On the algae flat, none of the pebbles were completely buried, and this plot contained the only pebbles in the experiment that did not sink at all.

Random faunal mixing may also have a pronounced effect on the orientation of concave-convex objects such as empty pelecypod shells. Where physical processes waves or currents - predominate, shells will lie predominantly concave side down, the most hydraulically stable position. Where random mixing occurs in quiet water at the sediment-water interface, however, concave-convex objects may tend to behave as loaded dice and preferentially develop a concave-side-up orientation (EMERY 1968). These differences in orientation permit an analysis of the relative effectiveness of waves and currents in ancient deposits.

In order to determine the effect of faunal mixing on shell orientation, nearly 1200 shells were placed near a coral reef on the sea floor at a depth of about $10 \mathrm{~m}$ and left for 40 days (CLIFTON 1971). The shells were divided among four plots, two 2 meters distant from the reef, two 6 meters distant. Each contained an identical assemblage of seven shell species in five different size classes. In two of the plots, one at 2 meters, one at 6 , all shells were placed concave side up; in the other two, all were placed concave side down. The bottom at the experiment site was not disturbed by waves or currents during the 40 days of observation; therefore, any changes in shell orientation that occurred during this time resulted from biogenic activity.

At the end of the experiment shell orientation was tabulated by size, species, and whether or not the shells were buried. Most of the shells (61.4\%) lay concave side up, demonstrating that faunal mixing can produce a surficial assemblage of dominantly concave-up shells. The concave-up tendency in general increased with increasing shell size, both overall and within individual species. The orientation also depends on shell shape - more of the rounder, more gibbous valves were rotated concave-up than flatter shells. About half of the shells became buried beneath the sediment surface during the experiment; of these $51.5 \%$ lay concave-up. In contrast, $70.6 \%$ of those shells remaining on the surface lay concave-up. Shells enclosed within the sediment where free movement to the most gravitationally stable position is inhibited may behave less like loaded dice and tend more toward a random orientation.

\section{SUMMARY}

1. Reef organisms may play a major role in the transport and distribution of sediment on the sea floor adjacent to coral reefs.

2. Some fish such as Malacanthus plumieri (BLOCH) selectively transport and collect certain types of sediment (such as larger coral and shell fragments).

3. The random movement of crawling or burrowing organisms may cause a large amount of sediment to be shifted laterally on the sea floor. On slopes, a net downhill displacement may result. 
4. The surface configuration and internal structure of the sediment is rapidly changed by faunal mixing. Ripple marks formed by waves or currents are obliterated by the activity of organisms in only a few weeks in the environment studied. Internal structure (bedding) near the sediment-water interface is similarly destroyed in a short period of time.

5. Larger clasts (including empty shells) on the sea floor tend to be buried by faunal undermining. The rate of burial depends primarily on the grain size of the substrate.

6. The random movement of fauna on the sea floor may produce a predominantly concave-up orientation of pelecypod shells and shell fragments on the sea floor - the opposite of that produced by the activity of waves or currents.

Acknowledgements. I am greatly indebted to my fellow team members during Tektite I and II, particularly Dr. R. E. HunTer of the U.S. Geological Survey who participated in all the research conducted during Tektite II. The manuscript was reviewed by R. HunTER and P. Quintzrno, who provided many helpful comments. Dr, E. Reimnitz, U.S. Geological Survey, kindly translated the abstract into German.

\section{LITERATURE CITED}

Clifton, H.E., 1971. Orientation of empty pelecypod shells and shell fragments in quiet water. J. sedim. Petrol. 41, 671-682.

- \& Hunter, R. E., a. The sand rilefish Malacantbus plumieri (Broch) and the distribution of coarse debris near West Indian coral reefs. Los Ang. County nat. Hist. Mus. Sci. Bull. 14 (In press).

- - b. Bioturbational rates and effects in carbonate sand, St. John, U.S. Virgin Islands. J. Geol. (In press).

- Mahinken, C. V. W., van Derwalker, J. C. \& Waller, R. A., 1970. Tektite I, Man-in-thesea project: marine science program. Science, N. Y. 168, 659-663.

Clovd, P. E., JR., 1959. Geology of Saipan, Mariana Islands, Part. 4. Submarine topography and shoal-water ecology. Prof. Pap. U.S. geol. Surv. 280-K, 361-445.

EMrRy, K. O., 1968. Positions of empty pelecypod valves on the continental shelf. J. sedim. Petrol. 38, 1264-1269.

Hoskin, C. M., 1963. Recent carbonate sedimentation on Alacran Reef, Yucatan, Mexico. Nat. Acad. Sci.-Nat. Res. Counc. Publ, 1089, 160 pp.

Hubbard, J. A. E. B., 1971. Sediment rejection by recent scleractinians: a key to coral distributions through time. Abstr. geol. Soc. Am. 3 (7), 607-608.

Author's address: Dr. H. E. CliftoN

U.S. Geological Survey

Menlo Park, California 94025

USA 